\title{
Story: A Butterfly? An Attractor?
}

\author{
JERRY AMEIS \\ University of Winnipeg (Canada)
}

\begin{abstract}
The vignette concerns a study that investigated engagement in mathematical problem solving under difficult conditions. It provides an example of dynamic research design, using chaos theory as a metaphor for both designing research and examining findings, and sets the stage for a later in-depth article about dynamic research design in education.
\end{abstract}

Current research design in education typically involves the creation of an explicit a priori well-defined path to follow. As we conduct the research, we might encounter a window that illuminates another path to follow, but our pre-designated path constrains us. We cannot follow the new path until a later time (when much may have changed about the conditions). We could refer to this as static research design. This stance on educational research is derived from a deterministic view of the universe where effects are continuous functions of causes and where predictions are possible if we can identify and control critical matters underlying phenomena (MacPherson, 1995).

Dynamic research design is different. It involves creating a broad path to follow, while hoping to illuminate paths to investigate along the way. The broad path does require a general explicit a priori pronouncement but any paths that might occur along the way cannot have such pronouncements (that would mean those paths were predictable from the onset). Chaos theory seems to support this kind of design. [Any distinction between chaos theory and complexity theory is not considered here. For purposes of this vignette, chaos theory concerns the behavior of complex chaotic systems, in which neither the components nor their interactions are simple to analyze and model, and where prediction is a slippery thing.] 
What follows is both an example of dynamic research design and of using chaos theory as a metaphor to seek explanations for findings. The example also sets the stage for a future article that considers dynamic research design in education in more detail.

\section{A study about engaging mathematical problem solving}

The study arose from a colleague's challenge - to engage children attending an afterschool daycare in significant mathematical activity. That challenge shaped the study's broad path - investigating engagement in mathematical problem solving under difficult conditions. That investigation involved pursuing whatever strategies seemed fruitful for engaging problem solving.

There was no stated-in-advance research question to constrict the nature and direction of the research. There was no explicit a priori conceptual framework delineated as the lens for analyzing the data. Being as "blind" as possible by minimizing knowledge and control of variables/factors/conditions and an evolving methodology were critical aspects of the design. Events occurring during the study could be used to shape subsequent directions of investigation and procedure. This seemingly simplistic design created a state of openness and "unease". [The reader may sense that we cannot be free of a priori conceptions. We have experiences embedded in our being that shape our thinking. The "trick" is minimizing their biasing effect on our research.]

There was no explicit prescribed methodology other than a plan for what to do on day 1 and a planned interview with individual children at the end of the study. The events for day 1 were planned ahead of time because some kind of activity had to occur. The interview with each child was intended to provide information about the children's relationship with and understandings of mathematics that existed prior to the study. This information might be useful, in the conventional sense, when analyzing the phenomena arising during the study. The interviews could have been conducted at the beginning of the study. However, doing so would have detracted from the state of "being blind", an essential feature of the research design. It also would have provided the children with a preliminary experience with this author that might have influenced their subsequent behaviour with respect to engagement in problem solving.

\section{The circumstances, events, observations, and results of the study}

The study was conducted from October through April in an after-school daycare setting with 16 children participating (eight boys and eight girls; seven children in grades 1 and 2, nine in grades 3 to 6). We met weekly on Fridays from about 4 P. M. to 5:30 P. M. While difficult conditions were anticipated in the daycare setting, they were not arranged for in advance. Their precise nature became apparent as the study proceeded. The difficult conditions that became evident were:

The children did not see Friday after school as a time to do mathematics. School was over; the weekend had arrived. This feeling was intensified by the fact that they came from six different classrooms. There was no critical mass of learners who saw each other as co-participants in mathematical activity. 
The children did not see me as a teacher with the accustomed authority inherent in that role. I was someone who was disturbing their comfortable routine of self-directed play while waiting for their parents.

There were significant distractions in the daycare room during the sessions. Parents picked up their children at any time.

When the daycare director told the children that I was there to do math with them, groans pervaded the room. At the very least, an attitude of disliking mathematics was present.

Two research design features contributed to the difficulty of the conditions. Each child had the choice of participating or not participating. Thus, there was uncertainty about the size and nature of the audience on any given Friday. As well, my intentional lack of knowledge about the children's mathematical understandings and classroom experiences made it difficult to design activities.

The situation was something like diving into a waterfall and being blind to the forces and hazards that lie beneath the surface. What to do under such interesting but difficult conditions? The question became especially poignant during the first session when I was confronted with exuberant youngsters intently playing build and crash and tease. Any thoughts about setting up a community of learners who inquire into and negotiate their own mathematical learning seemed somehow far-fetched in that environment.

The plan for day 1 was to present mathematical problems in an entertaining way. [This seemed a sensible way to begin.] The plan continued for two more sessions. They consisted of what could be described as a chautauqua show (song and dance sprinkled with serious stuff). The children who participated at the start of the session (about twothirds of them) watched me perform mathematics magic tricks and were invited to engage in non-routine mathematical problem solving. The show and invitation did not lead to desired results. The children's attention wandered back and forth between play and problem solving, drifting eventually almost exclusively to play. It was time to change the approach.

The idea of reading a fantasy adventure story with mathematical problems embedded in it came to me after the third session. That evening I began to imagine and to write. Not wishing to be too optimistic, the first chapter was only two pages long. It included drawings of exotic characters and a single problem that involved decoding a message that consisted of numbers.

The children were organized into two groups for the fourth session: grades 1 and 2 combined and grades 3 to 6 combined. I read chapter one to the older group after directing the younger group to engage in non-routine mathematical problem solving. The younger group was soon seriously off-task. Their noisy play made the story reading troublesome. The older group also contributed to the pandemonium because the decoding problem was too difficult. [They did try to solve it.] Nevertheless something promising was emerging. Even though the decoding problem frustrated the older group, they became interested in the story. This encouraged me to write chapter two. 
The fifth session involved reading chapter two to the older group after directing the younger group to engage in non-routine problem solving. As before, the younger group quickly lost focus and did distracting things. But this time some of them wandered over to listen to the story. Most of the older group became absorbed in it and showed interest in solving the problems.

For the sixth session, I decided to involve the younger group in the story as well - a decision that required two levels of problems (one for each group). The result was promising. The story captured the attention of many of the children and most of them wanted to solve the problems. By this time all of the children participated at the start of the session but a few did wander away to play at some point. Order, in the street sense, was emerging out of literal chaos.

The evident willingness of most of the children to engage in story-based problem solving was an inviting window along the broad research path. The decision was made to see where it might lead. To this point, the study had been driven by a purpose rather than a question. The window-generated question became: Can story-based problems sustain engagement in mathematical problem solving under difficult conditions? What might explain the continuance (or suspension) of engagement?

From this point on, no other inviting windows appeared that might suggest altering or abandoning the question. The story reading continued to engage children in mathematical problem solving. Each subsequent Friday involved reading the story (consisting of six chapters by the end) in a partly interactive and playful manner until a problem was encountered; waiting for the children to work on a solution before discussing it; then continuing with the story until another problem was encountered.

With few exceptions, the children eagerly attempted to solve the problems embedded in the story. A typical problem-solving event involved the children going their separate ways to work on a solution, with only occasional communication with another student(s) about a possible answer. After some time had passed, one or more children rushed to me, asking if the solution was correct. I usually had to tell them that something was not quite okay and then provided suggestions. They went back to working on the problem. I called the children back together again when I felt that they were losing patience, or infrequently, when a number of them had found a solution.

The children's enthusiasm and diligence increased as the study progressed. By late February, most of them could detect when a problem was coming and excitedly asked for it. Often they asked their parents to wait until they finished working on a problem.

It was evident that the majority of the problems were quite challenging. The children's solution paths did not usually lead to success even after I had provided assistance. They typically made arithmetic errors, chose the wrong arithmetic operation, and/or had misconceptions about a problem. Nevertheless, I continued with difficult problems in the story. The following problem is typical. The complexity was designed for the older group. The younger group's version involved fewer steps for the stairs. 
Sample problem

Once on the ledge, they quickly followed Chadus' lead and pressed themselves tightly against the face of the cliff and closed their eyes. Boulders thundered down all around them, just missing them. The noise was deafening. Minutes later the rain of boulders stopped. No one was hurt, just scared. Cheka broke the silence,

"That was close. Now how do we get back up to the road? It is too high to reach and the cliff is impossible to climb."

Plasto had an idea. He took a piece of paper from his packsack and sketched a side and back view of the stairs. He pointed to his drawing.

side view

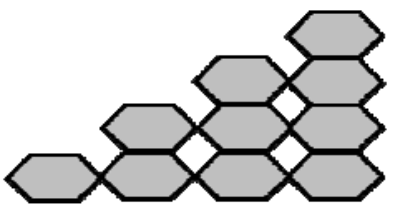

back view

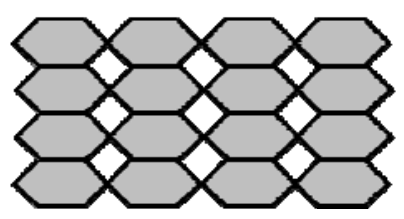

"We have to build stairs that look like this. But first we must collect enough rocks to build them. Luckily, when some of the boulders hit the ledge, they broke up into rocks of about the right size. I wonder how many we need to find?"

Scorby came over, looked at the drawing, and started thinking.

How many rocks are needed to build the stairs?

The individual interviews at the conclusion of the study involved asking questions and providing mathematical tasks. The questions concerned their attitude towards mathematics, how their teachers taught mathematics, and their school experiences with mathematical problem solving. The mathematical tasks concerned number strand outcomes that were appropriate to the children's grade level. The findings indicated that their mathematical understandings were generally weak, their classroom experiences only infrequently involved mathematical problem solving, with completion of 
worksheets the instructional norm. Also, there was further evidence that most of them did not like mathematics.

\section{A search for explanation through conventional lenses}

What might explain the children's willingness to engage in the story-based problem solving even though they struggled with many of the problems, often achieving only limited success? Their behaviour was not what one would expect of children at the end of a school week when given a choice of go and play or come and struggle with a mathematical problem. The information from the individual interviews made their behaviour seem more perplexing. Most of the children's mathematical skills and understandings were weak and they did not enjoy mathematics. Yet, they engaged in mathematical problem solving even though they were aware they were doing mathematics. We could seek explanations in conventional arenas such as motivation theory, the nature of children, and constructivist theory and its implications for practice. Instead, we will explore another possibility involving chaos theory as a metaphor.

\section{A search for explanation through a metaphorical sense of chaos theory}

The compelling explanation for the children's engagement in problem solving seems to concern 'story'. The children's engagement with problem solving drifted back and forth until the story reading began. The story seemed to attract them to pay significant attention to problem solving. This is somewhat puzzling because the story was not a finely crafted piece of writing full of marvelous imagery. It was an unpolished draft in which the embedded problems sometimes were not as naturally fitting as one might desire and where the writing was clumsy at times. How could such a story bring about a large change in behaviour?

It may be fruitful to consider the situation through a metaphorical lens concerning chaos theory. Three notions may be apropos here: attractor, strange attractor, and "butterfly". An attractor(s) can be a single point to which phenomena gather, two points between which phenomena oscillate, or more complex than that (Schroeder, 1991). A strange attractor concerns veering away from a point attractor (or oscillating points) to a different point. A 'butterfly' is a popularized version of the notion that chaotic complex systems are sensitive to initial conditions.

Prior to my using story-based problems, the children's attention oscillated between self-directed play and minor attention to nonstory-based problem solving. The underlying attractors at work there may concern nature and nurture. A desire for play may be hard-wired in us. The children's minor attention to problem solving may be due to socialization processes involved in schooling and parenting where an adult asks children to do something and they are expected to comply. In the case of the nonstorybased problems, this author invited the children to participate and a good number did initially participate (but in a limited way). Because they were not required to continue participating, they were freed from adherence to adult requests. Self-directed play 
seemed more "attractive" and they tended to drift back to it (the initial state before they were invited to problem solve).

After the story reading began, the students' behaviour shifted dramatically towards engagement in problem solving. Can this be seen as a strange attractor or a butterfly at work? The author prefers to view it as a strange attractor, something that brings about a significant shift in a phenomenon, rather than as a butterfly at work. It is a stretch to see 'story' here as being about sensitivity to initial conditions. Too much activity involving promotion of problem solving had already occurred to see 'story' as being about a change in initial conditions.

'Story' may also be hard-wired in us. We may have an innate need to create and to consume stories. If this has validity, then 'story' cannot simply refer to an oral or written vehicle of communication. Story must be understood in the larger sense of communication through words, paintings, sculpture, dance, music, pantomime, and so on.

Notions of hard-wiredness take us into the realm of the unconscious, the emotional, and the irrational, in short, into the realm of nature. This realm is where some attractors may be found - seemingly simple innate forces or tendencies that have significant power for moving us towards particular behaviours. Attractors may also be found in the realm of nurture - our social arrangements and processes. Attractors from nature and nurture may conflict with each other, leading possibly to an oscillation between two or more kinds of behaviour. They may support each other, leading possibly to a single stable behaviour. Chaos theory as a metaphor underlying educational research may open the door to speculations (and investigations) about the dual impact of nature and nurture on teaching and learning, impacts that have for too long been like two solitudes wandering in the wilderness.

\section{References}

MacPherson, E. D. 1995. Chaos in the curriculum. Journal of Curriculum Studies, 27(3), 263-279.

Schroeder, M.. 1991. Fractals, Chaos, Power Laws. W. H. Freeman and Company, New York.

About the Author

Jerry Ameis is an associate professor of mathematics education who teaches mathematics and mathematics methods courses to education access students. His research interests concern how children learn mathematics and the kind of mathematics they can learn. His view of teaching and learning borrows from the fundamental notions of chaos theory where predictability is suspect. Translated into educational research and practice, this means that we must beware of our fondness for using narrow lenses to view phenomena and our penchant for adopting bandwagon approaches to pedagogy. His e-mail address: is: j.ameis@uwinnipeg.ca

(C) Copyright 2009. The author, JERRY AMEIS, assigns to the University of Alberta and other educational and non-profit institutions a non-exclusive license to use this document for personal use and in courses of instruction provided that the article is used in full and this copyright statement is reproduced. The author also grants a non-exclusive license to the University of Alberta to publish this document in full on the World Wide Web, and for the document to be published on mirrors on the World Wide Web. Any other usage is prohibited without the express permission of the author. 